\title{
Pharmacokinetics of a Cytochrome P450 2E1 Probe, Chlorzoxazone, and its 6-Hydroxy Metabolite in Poloxamer 407-Induced Hyperlipidemic Rats
}

\author{
Mi Hye Kwon, Cheol Jung Lee, Yong Yeon Cho, Hee Eun Kang \\ College of Pharmacy and Integrated Research Institute of Pharmaceutical Sciences, The Catholic University of Korea, \\ Bucheon, Gyeonggi-Do 420-743, South Korea
}

Received, August 8, 2013; Revised, September 18, 2013; Accepted, October 15, 2013; Published, November 6, 2013

\begin{abstract}
Purpose. To evaluate the possible changes in CYP2E1 expression and activity in hyperlipidemia (HL), we evaluated the pharmacokinetics of chlorzoxazone (CZX) as a CYP2E1 probe in rats with HL induced by poloxamer 407 (HL rats). Methods. The pharmacokinetics of CZX and its 6hydroxy metabolite (OH-CZX) were evaluated after intravenous administration of $20 \mathrm{mg} / \mathrm{kg} \mathrm{CZX}$ to both control and HL rats. We also examined changes in the expression of CYP2E1 and its in vitro metabolic activity in hepatic microsomal fractions from HL rats. Results. The total area under the plasma concentration-time curve (AUC) of CZX in the HL rats after its intravenous administration was comparable with that in the controls due to unchanged non-renal clearance $\left(\mathrm{CL}_{\mathrm{NR}}\right)$. The $\mathrm{AUC}$ of $\mathrm{OH}-\mathrm{CZX}$ and $\mathrm{AUC} \mathrm{OH}_{\mathrm{OH}}$ ${ }_{\mathrm{CZX}} / \mathrm{AUC}_{\mathrm{CZX}}$ ratios in $\mathrm{HL}$ rats also remained unchanged. This was primarily due to the comparable hepatic $\mathrm{CL}_{\text {int }}$ for metabolism of CZX to OH-CZX via CYP2E1 between the control and HL rats as a result of unchanged expression of CYP2E1 in HL rats. Conclusions. This is the first study to evaluate CYP2E1 expression and activity in HL rats and their effects on the pharmacokinetics of a CYP2E1 probe drug. These findings have potential therapeutic implications assuming that the HL rat model qualitatively reflects similar changes in patients with HL.
\end{abstract}

This article is open to POST-PUBLICATION REVIEW. Registered readers (see "For Readers") may comment by clicking on ABSTRACT on the issue's contents page.

\section{INTRODUCTION}

Hyperlipidemia (HL) involves abnormally elevated levels of one or more plasma lipids (cholesterol, cholesteryl esters, triglycerides, or phospholipids) and/or lipoproteins. This elevation in plasma lipids may be caused by a primary genetic defect or may be secondary to diet, drugs, or disease (1). Plasma lipid profile abnormalities potentially lead to changes in the pharmacokinetics of drugs. A significantly reduced time-averaged total body clearance (CL) has been reported for nifedipine $(2,3)$, amiodarone $(4,5)$, nelfinavir $(6)$, clomipramine (7), and docetaxel (8) in rats with HL (HL rats). In HL rats, both the unbound fraction in plasma and the apparent steady-state volume of distribution $\left(V_{\mathrm{ss}}\right)$ of some drugs (amiodarone, nelfinavir, clomipramine, and docetaxel) also display a tendency to decrease due to increased plasma lipoprotein levels (5-8).

A decrease in liver metabolic enzyme expression, including a reduced expression of hepatic microsomal cytochrome P450 (CYP) $3 \mathrm{~A} 1 / 2$ (by $51.9 \%$ for $3 \mathrm{~A} 1$ and by $38.4 \%$ for $3 \mathrm{~A} 2$ ) and $2 \mathrm{C} 11$ (by $39.6 \%$ ), is observed in an HL rat model (4). In primary rat hepatocytes exposed to lipoprotein-rich serum, reductions in mRNA for cytochrome P450 1A1, 3A2, and 2D1, and some transporters are reported (9). We have found that the metabolic clearance of carbamazepine (10) and verapamil (11), substrates of the CYP3A subfamily, is reduced in HL rats. Moreover, 4hydroxylation of tolbutamide, which is mediated via CYP2C11, is also reduced in HL rats (our unpublished data). These results show that reduced expression of hepatic CYP $3 \mathrm{~A} 1 / 2$ or $2 \mathrm{C} 11$ in HL rats causes metabolic deficiency of CYP3A or 2 C11 substrates in vivo.

However, to our knowledge, the hepatic CYP2E1 expression level in HL rats has never been reported. CYP2E1 metabolizes important xenobiotics - such as ethanol-and is capable of activating xenobiotics - such as nitrosaminesto hepatotoxic products (11). It also initiates the lipid peroxidation process, produces free radicals,

Corresponding Author: Prof. Hee Eun Kang, Ph.D., College of Pharmacy, The Catholic University of Korea, Bucheon, Gyeonggi-Do 420-743, South Korea, E-mail: kanghe@catholic.ac.kr 
and contributes to oxidative stress resulting in cell damage. Because fatty acids are both substrates and inducers of CYP2E1 (12), alterations of hepatic CYP2E1 expression are likely in HL rats. Therefore, it is important to evaluate the possible changes of CYP2E1 expression and activity in the HL condition.

We examined changes in the expression of CYP2E1 in a well-established poloxamer 407induced HL rat model. We also evaluated the pharmacokinetics of chlorzoxazone (CZX, 5chloro-3H-benzooxazol-2-one) and its major metabolite, 6-hydroxy CZX (OH-CZX) as probes for CYP2E1 activity after intravenous administration of CZX to both control and HL rats. OH-CZX formation has been used as a chemical probe to assess the activity of CYP2E1 both in vitro and in vivo because of its good correlation with CYP2E1 activity in both humans and rats $(13,14)$. The in vitro metabolic activity of CYP2E1 in hepatic microsomal fractions from HL rats was also evaluated with CZX.

\section{MATERIALS AND METHODS}

\section{Materials and Reagents}

CZX, OH-CZX, 5-(4'-hydroxyphenyl)-5phenylhydantoin (4'-HPPH, internal standard for high-performance liquid chromatographic [HPLC] analysis of CZX and OH-CZX), poloxamer 407 (Pluronic ${ }^{\circledR}$ F-127), the reduced form of $\beta$-nicotinamide adenine dinucleotide phosphate (NADPH; as the tetrasodium salt), $\beta$ glucuronidase (type $\mathrm{H}-1$, from Helix pomatia with a $\beta$-glucuronidase activity of $3,854,000$ units/g and a sulfatase activity of 27,310 units/g), and Tris(hydroxymethyl)aminomethane (Tris)-buffer were purchased from Sigma-Aldrich Corporation (St. Louis, MO, USA). Polyclonal rabbit anti-rat CYP2E1 antibody was purchased from Detroit R\&D (Detroit, MI, USA). Horseradish peroxidase-conjugated goat anti-rabbit antibody and $\beta$-actin antibody were products from Santa Cruz Biotechnology (Santa Cruz, CA, USA). Zoletil $50^{\circledR}$ (tiletamine hydrochloride + zolazepam hydrochloride) was a product from Virbac (Carros, France). Other chemicals were of reagent or HPLC grade.

\section{Animals}

The animal study protocols were approved by the Department of Laboratory Animals, Institutional Animal Care and Use Committee (IACUC) of Sungsim Campus, The Catholic University of Korea, Seoul, South Korea. Male Sprague-
Dawley rats (7-8 weeks old, 265-310 g) were purchased from OrientBio (Sung Nam, South Korea). The procedures used for housing and handling of rats were similar to those described previously $(10,11)$.

\section{Induction of $\mathrm{HL}$}

Rats were randomly divided into HL and control groups. To induce HL, $400 \mathrm{mg}$ (in $5 \mathrm{~mL}$ ) $/ \mathrm{kg}$ of poloxamer 407 (dissolved in cold sterile $0.9 \%$ $\mathrm{NaCl}$ solution and refrigerated overnight to facilitate its dissolution) was injected intraperitoneally (i.p.) into the rats $(10,11)$. Control rats received the same volume of vehicle alone (cold sterile $0.9 \% \mathrm{NaCl}$ solution). Pharmacokinetic experiments were conducted $36 \mathrm{~h}$ after administration of poloxamer 407 or vehicle (10).

\section{Immunoblot Analysis of CYP2E1}

The procedures used for the preparation of hepatic microsomes from control $(n=6)$ and HL $(n=6)$ rats were similar to methods reported previously (15). The protein content in hepatic microsomes was measured using the Bradford assay (16).

Hepatic microsomes containing equal amounts of protein (10 $\mu \mathrm{g}$ per lane; $n=5$, each) were resolved by $10 \%$ sodium dodecyl sulfatepolyacrylamide gel electrophoresis (SDS-PAGE) and transferred onto polyvinylidene difluoride (PVDF) membranes. The membranes were blocked for $1 \mathrm{~h}$ in 5\% skim milk powder in phosphate buffered $0.9 \% \mathrm{NaCl}$ solution containing $0.05 \%(\mathrm{v} / \mathrm{v})$ Tween $20($ PBS-T). For immunodetection, blots were incubated overnight at $4^{\circ} \mathrm{C}$ with rabbit anti-CYP2E1 antibody (diluted $1: 5000$ in PBS-T containing 3\% skim milk powder), followed by incubation for $1 \mathrm{~h}$ at room temperature with anti-rabbit secondary antibody (diluted 1:5000 in PBS-T containing 3\% skim milk powder). Western blots were visualized with an enhanced chemiluminescence detection system (Amersham Biosciences, Piscataway, NJ, USA) using a Chemidoc XRS imager system (Bio-Rad Laboratories, Hercules, CA, USA). The $\beta$-actin band was used as a loading control.

\section{Measurement of Formation Kinetics of OH-CZX from CZX in Hepatic Microsomal Fractions}

The methods used for the measurement of $V_{\max }$, $K_{\mathrm{m}}$, and $\mathrm{CL}_{\text {int }}$ for the formation of OH-CZX from CZX in hepatic microsomes were similar to those reported previously (14). The following components were mixed: the above hepatic microsomes from each group (equivalent to 0.2 
mg protein), $0.1 \mathrm{M}$ Tris- $\mathrm{HCl}$ buffer (pH 7.4), and $5 \mu \mathrm{L}$ of methanol containing CZX (final CZX concentrations of $2.5,5,10,20,50,100,200,500$, and $1000 \mu \mathrm{M})$. Mixtures were preincubated for 5 min in a thermomixer (Thermomixer 5436; Eppendorf, Hamburg, Germany) at $37^{\circ} \mathrm{C}$ and 600 rpm. To initiate the reaction, NADPH (in Tris$\mathrm{HCl}$ buffer of $\mathrm{pH} 7.4$ to a final concentration of 1 $\mathrm{mM}$ ) was added to a final volume of $250 \mu \mathrm{L}$. After incubation for $20 \mathrm{~min}$, an aliquot of $50 \mu \mathrm{L}$ was transferred to an Eppendorf tube containing $25 \mu \mathrm{L}$ of methanol with $10 \mu \mathrm{g} / \mathrm{mL}$ of $4^{\prime}-\mathrm{HPPH}$ (internal standard for $\mathrm{OH}-\mathrm{CZX}$ ) and $1 \mathrm{ml}$ of methyl tertiary butyl ether (MTBE), and vortexmixed to terminate the reaction. The mixture was then treated following the sample preparation procedure. All of the above microsomal incubation conditions were within the linear range of the reaction rate. The kinetic constants $\left(K_{\mathrm{m}}\right.$, apparent Michaelis-Menten constant, and $V_{\max }$, maximum velocity) for formation of $\mathrm{OH}-\mathrm{CZX}$ were calculated using a nonlinear regression method (17). The unweighted kinetic data from microsomes were fitted to a single-site MichaelisMenten equation: $V=V_{\max } \times[\mathrm{S}] /\left(K_{\mathrm{m}}+[\mathrm{S}]\right)$, where $[\mathrm{S}]$ is the substrate (CZX) concentration. The $\mathrm{CL}_{\text {int }}$ (intrinsic clearance) for the formation of OH-CZX was calculated by dividing $V_{\max }$ by $K_{\mathrm{m}}$.

\section{Measurement of CZX Plasma Protein Binding}

Protein binding of CZX to fresh rat plasma $(n=5)$ was assessed by equilibrium dialysis $(10,11)$. Fresh plasma $(0.2 \mathrm{~mL})$ was dialyzed against 0.2 $\mathrm{mL}$ of isotonic Sørensen phosphate buffer $(\mathrm{pH}$ 7.4) containing $3 \%(\mathrm{w} / \mathrm{v})$ dextran ("the buffer") to minimize volume shift (18) using a $0.25-\mathrm{mL}$ micro-equilibrium dialyzer (Harvard Apparatus, Holliston, MA) and a regenerated cellulose membrane with a molecular weight cut-off of 10 $\mathrm{kDa}$ (Harvard Apparatus). To reduce the equilibrium time of CZX between the buffer and plasma compartments, the drug was spiked into the plasma side (19) to a final concentration of 5 $\mu \mathrm{g} / \mathrm{mL}$. Because the protein binding of CZX to fresh rat plasma remained constant at $67.3 \%$ to $68.3 \%$ for CZX concentrations of 1 to $50 \mu \mathrm{g} / \mathrm{mL}$ (20), $5 \mu \mathrm{g} / \mathrm{mL}$ of CZX was chosen in this study. The spiked dialysis cell was incubated in a waterbath shaker kept at $37^{\circ} \mathrm{C}$ at a rate of 50 oscillations per min (opm). After $24 \mathrm{~h}$, two $50-\mu \mathrm{L}$ aliquots were removed from each compartment and stored at $-20^{\circ} \mathrm{C}$ until HPLC analysis.

\section{Intravenous Administration of CZX to Rats}

The procedures used for pretreatment of rats, including cannulation of the jugular vein (for drug administration in the intravenous study) and the carotid artery (for blood sampling), were similar to those reported previously $(10,11)$. Zoletil $50^{\circledR}$ (intramuscular injection at a dose of $40 \mathrm{mg} / \mathrm{kg}$ $[0.8 \mathrm{~mL} / \mathrm{kg}])$ was employed instead of inhalation anesthetics to minimize the effect on CYP2E1 (21), because diethyl ether and isoflurane anesthesia reportedly increase CYP2E1 activity (22). The rats were allowed to recover from the anesthetics overnight and were not restrained during the experiment.

For analysis of plasma lipid profiles, 400 $\mu \mathrm{L}$ of blood ( $200 \mu \mathrm{L}$ of plasma) were obtained from each rat immediately before the start of the experiment. CZX, dissolved in distilled water (an adjusted $\mathrm{pH}$ of 8.5$)$ with a minimal amount $(5 \mu \mathrm{L} /$ $1 \mathrm{~mL}$ ) of $10 \mathrm{~N} \mathrm{NaOH}$ at a dose of $20 \mathrm{mg}$ (in 2 $\mathrm{mL}) / \mathrm{kg}(14,20)$, was manually infused over 1 min via the jugular vein of control $(n=9)$ and HL rats $(n=10)$. Blood samples (approximately 0.12 $\mathrm{mL}$ ) were collected via the carotid artery at 0 (control), 1 (end of infusion), 5, 15, 30, 45, 60, 90, 120, and 180 min after the start of intravenous infusion. A $0.3 \mathrm{~mL}$ of heparinized $0.9 \% \mathrm{NaCl}-$ injectable solution (20 units $/ \mathrm{mL}$ ) was used to flush the cannula immediately after each blood sampling to prevent blood clotting. Based on our previous preliminary study (10), this heparin dose might not influence triglyceride level significantly. Blood samples were immediately centrifuged, and $50 \mu \mathrm{L}$ of plasma were collected in 1.5-mL polyethylene tubes and stored at $-20^{\circ} \mathrm{C}$ until used for HPLC analysis of CZX and OHCZX. At the end of the experiment ( $24 \mathrm{~h}$ after CZX treatment), each metabolic cage was rinsed with $20 \mathrm{~mL}$ of distilled water, and the rinse water was combined with a urine sample. The volume of the combined urine sample was determined, and two $50-\mu \mathrm{L}$ aliquots were stored at $-20^{\circ} \mathrm{C}$ until HPLC analysis.

\section{HPLC Analysis of CZX and OH-CZX}

Concentrations of CZX and OH-CZX were determined by HPLC according to previously described methods $(14,23)$ with slight modifications. Briefly, a $0.1-\mathrm{mL}$ aliquot of $0.2 \mathrm{M}$ sodium acetate buffer ( $\mathrm{pH} 4.75$ ), a $0.1-\mathrm{mL}$ aliquot of isotonic Sørensen phosphate buffer $(\mathrm{pH}$ 7.4) containing 200 units of $\beta$-glucuronidase, $25 \mu \mathrm{L}$ of methanol containing 4'-HPPH (internal standard: $10 \mu \mathrm{g} / \mathrm{mL}$ ), and $1 \mathrm{~mL}$ of MTBE (extraction solvent) were added to $50 \mu \mathrm{L}$ of sample. The resulting mixture was vortex-mixed and centrifuged. The upper organic layer was transferred and evaporated under a gentle stream of nitrogen gas at $50^{\circ} \mathrm{C}$. The residue was 
reconstituted in $100 \mu \mathrm{L}$ of a $1: 1$ mixture $(\mathrm{v} / \mathrm{v})$ of 2 $\mathrm{mM}$ ammonium acetate and acetonitrile, and 20 $\mu \mathrm{L}$ were directly injected onto a $\mathrm{C}_{18}$ HPLC column $(5 \mu \mathrm{m}, 250 \times 4.60 \mathrm{~mm}$; Phenomenex, Torrance, CA, USA). The mobile phase $(20 \mathrm{mM}$ ammonium acetate:acetonitrile $=64: 36[\mathrm{v} / \mathrm{v}]$ for plasma and other samples excluding urine samples and $68: 32[\mathrm{v} / \mathrm{v}]$ for urine samples) was run at a flow rate of $1.0 \mathrm{~mL} / \mathrm{min}$, and the column eluent was monitored at $283 \mathrm{~nm}$ using an ultraviolet detector. Unconjugated concentrations of OH-CZX were also measured in urine samples without incubation with $\beta$-glucuronidase. The retention times of $\mathrm{OH}-\mathrm{CZX}, \mathrm{CZX}$, and 4'-HPPH (internal standard) in plasma and other samples excluding urine samples were approximately 4.6, 10.7 , and $5.5 \mathrm{~min}$, respectively. Those in urine samples were 5.1, 13.6, and 6.9 min, respectively. The lower limit of quantification of both $\mathrm{OH}-\mathrm{CZX}$ and CZX in plasma samples was 50 $\mathrm{ng} / \mathrm{mL}$. The values in urine samples were 250 and $50 \mathrm{ng} / \mathrm{mL}$ for OH-CZX and CZX, respectively. The relative errors of assay accuracy were below $16.4 \%$, and the coefficients of variation $(\mathrm{CVs})$ of the analysis were below $12.5 \%$.

\section{Pharmacokinetic Analysis}

The total area under the plasma concentrationtime curve from time zero to infinity (AUC) was calculated using the trapezoidal rule-extrapolation method (24), which uses the logarithmic trapezoidal rule to calculate the area during the phase of declining plasma level, and the linear trapezoidal rule for the phase of rising plasma level. The area from the last datum point to time infinity was estimated by dividing the last measured plasma concentration by the terminalphase rate constant.

Standard methods (25) were used to calculate the following pharmacokinetic parameters by non-compartmental analysis (WinNonlin; Pharsight Corporation, Mountain View, CA, USA): the time-averaged total body, renal, and non-renal clearances $\left(\mathrm{CL}, \mathrm{CL}_{\mathrm{R}}\right.$, and $\mathrm{CL}_{\mathrm{NR}}$, respectively); terminal half-life; mean residence time (MRT); and apparent steady-state volume of distribution $\left(V_{\mathrm{ss}}\right)$. The peak plasma concentration $\left(C_{\max }\right)$ and time to reach $\mathrm{C}_{\max }\left(T_{\max }\right)$ were read directly from the experimental data.

\section{Statistical Analysis}

Differences between the two means for unpaired data were analyzed using Student's $t$-test, and $p<$ 0.05 was taken to indicate statistical significance. All data are presented as means \pm SD unless otherwise specified.

\section{RESULTS}

\section{Protein Expression of Hepatic CYP2E1}

The protein levels of hepatic CYP2E1 within hepatic microsomal fractions from control and HL rats are shown in Figure 1. The protein expression of hepatic CYP2E1 in HL rats was comparable with that of controls.

\section{Formation Kinetics of OH-CZX from CZX in Hepatic Microsomal Fractions}

The mean OH-CZX formation velocities in hepatic microsomal fractions from control and HL rats are shown in Figure 2. The $V_{\max }, K_{\mathrm{m}}$, and $\mathrm{CL}_{\text {int }}$ values for the formation of $\mathrm{OH}-\mathrm{CZX}$ in hepatic microsomal fractions from both groups are listed in Table 1. Although the $V_{\max }$ value in HL rats was significantly slower (by $36.9 \%$ ) than that in controls, the $K_{\mathrm{m}}$ and $\mathrm{CL}_{\text {int }}$ values were comparable between the two groups. This suggests that the hepatic metabolic activity of hydroxylation of CZX in HL rats is comparable with that of control rats.

\section{Plasma Protein Binding of CZX}

Plasma protein binding of CZX was comparable between control and HL rats $(67.5 \% \pm 16.3 \%$ and $65.0 \% \pm 8.67 \%$ for control and HL rats, respectively). The recovery of CZX from the dialysis apparatus was almost complete $(81.6 \% \pm$ $6.12 \%)$.

\section{Pharmacokinetics of CZX and OH-CZX after Intravenous Administration of CZX}

The mean arterial plasma concentration-time profiles of CZX and $\mathrm{OH}-\mathrm{CZX}$ after intravenous administration of $20 \mathrm{mg} / \mathrm{kg} \mathrm{CZX}$ to control and $\mathrm{HL}$ rats are shown in Figures $3 \mathrm{~A}$ and $3 \mathrm{~B}$, respectively. The relevant pharmacokinetic parameters and plasma lipid profiles of each group are listed in Table 2. The pharmacokinetic parameters of CZX and OH-CZX were comparable between control and HL rats.

\section{DISCUSSION}

We chose poloxamer 407 to induce HL in rats because its i.p. administration shows no apparent toxicity (4). Poloxamer 407-induced hypertriglyceri-demia and hypercholesterolemia are well-documented phenomena: triglyceride levels are elevated due to inhibition of lipoprotein lipase (26) and hypercholesterolemia due to the indirect stimulation of the activity of 3-hydroxy3-methylglutaryl coenzyme A (HMG CoA) 
A

CYP2E1

$\beta$-actin

B
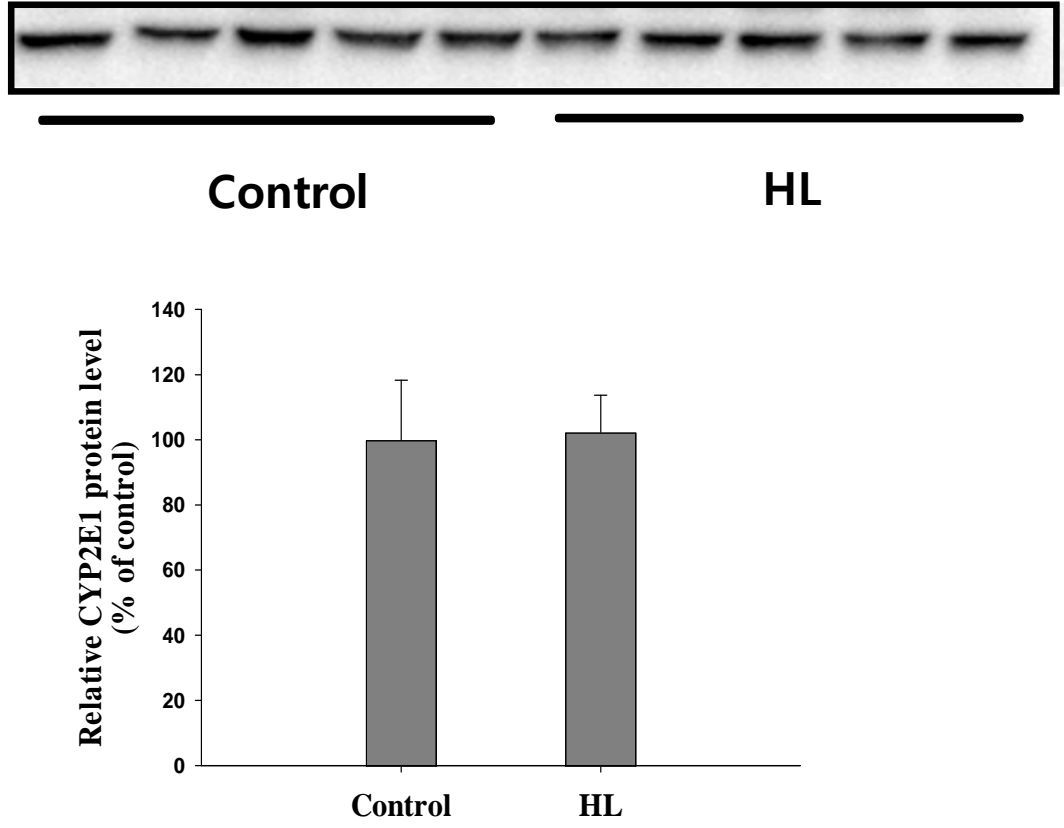

Figure 1. Hepatic protein expression of CYP2E1 in HL and control rats was quantitated by immunoblotting and densitometry of microsomal fraction ( $10 \mu \mathrm{g}$ of protein) from each rat liver ( $n=5$ each) (A). The protein expression (mean $\pm \mathrm{SD}$ ) was expressed in terms of percentage of the control rats, $100 \%$ (B). The $\beta$-actin band was used as a loading control.

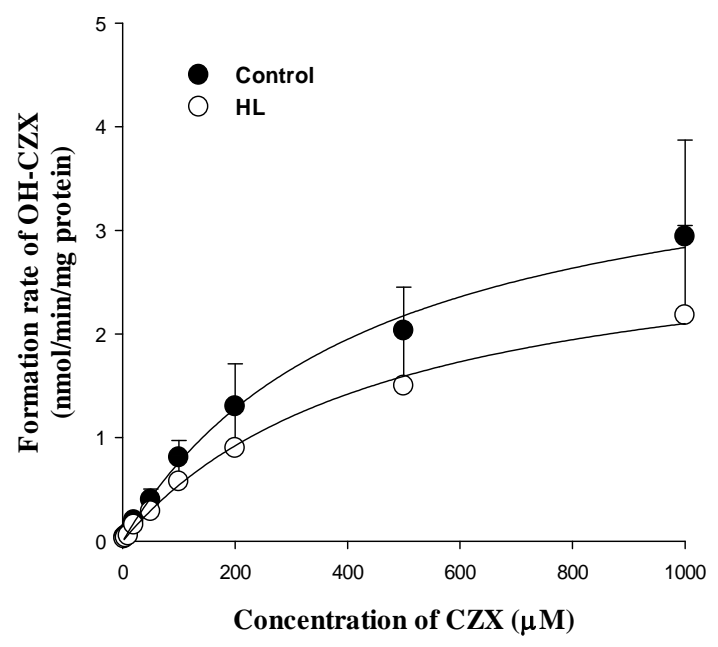

Figure 2. Mean velocities for the formation of $\mathrm{OH}-\mathrm{CZX}$ (mean $\pm \mathrm{SD}$ ) from various concentrations of CZX in the hepatic microsomal fraction of control and HL rats ( $n=6$ each).
Table 1. In vitro $V_{\max }, K_{\mathrm{m}}$, and $\mathrm{CL}_{\text {int }}$ for the formation of OH-CZX from CZX (mean \pm SD) in hepatic microsomal fraction of control and HL rats.

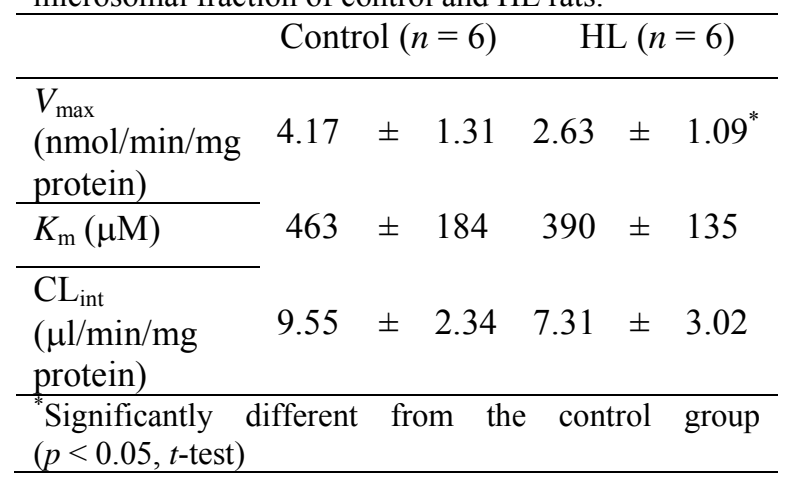


reductase, the rate-limiting enzyme in cholesterol biosynthesis, and decreased LDL receptor expression in the liver $(27,28)$. The results of our previous study indicated that hypertriglyceridemia and hypercholesterolemia were induced following i.p. administration of poloxamer 407, with no significant hepatic or kidney toxicities (10). The induction of $\mathrm{HL}$ was confirmed based on the significant increase in total cholesterol $(>220$ $\mathrm{mg} / \mathrm{dL})$ and triglyceride $(>200 \mathrm{mg} / \mathrm{dL})$ levels following the analysis of the plasma lipid profiles prior to the pharmacokinetic studies (Table 2).

CZX dose for this study $(20 \mathrm{mg} / \mathrm{kg})$ was in the intravenous dose range of 15 to $50 \mathrm{mg} / \mathrm{kg}$, which showed linear disposition of CZX (29). The pharmacokinetic parameters of CZX in control rats (Table 2) were similar to those in previous pharmacokinetic studies on CZX including CL $(8.96-12.3 \mathrm{~mL} / \mathrm{min} / \mathrm{kg})$ and $V_{\mathrm{ss}}$ $(279-391 \mathrm{~mL} / \mathrm{kg})$ values $(14,20,23,30)$.

In HL rats, the AUC of intravenous CZX was comparable with that in controls because of a similar CL of CZX (concretely $\mathrm{CL}_{\mathrm{NR}}$ ) (Table 2). The $C_{R}$ values of CZX in both groups of rats were comparable and made a negligible contribution $(\sim 1 \%)$ to the CL of CZX (Table 2$)$. Moreover, considerable recovery of total (free + conjugated) $\mathrm{OH}-\mathrm{CZX}$ in the urine $(86.6 \%$ and $102 \%$ of CZX dose for control and HL rats, respectively, Table 2) indicates that most of the intravenous CZX dose is eliminated via the 6hydroxylation of CZX followed by conjugation reaction and urinary excretion of the metabolite. Therefore, the $\mathrm{CL}_{\mathrm{NR}}$ of CZX in HL rats is related to the metabolic clearance of CZX to OH-CZX. CZX has a low to intermediate hepatic extraction ratio in rats $(0.087-0.681$ in perfused rat liver; 0.317 by estimation based on $\mathrm{CL}_{\mathrm{NR}}$ of control rats [Table 2] and hepatic plasma flow rate [29.8 $\mathrm{mL} / \mathrm{min} / \mathrm{kg}$ in rats]) $(13,31)$. Therefore, hepatic clearance of CZX depends primarily on its hepatic intrinsic clearance $\left(\mathrm{CL}_{\mathrm{int}}\right)$ and free fraction in plasma, and possibly on the hepatic blood flow rate (32). In $\mathrm{HL}$ rats, the $\mathrm{CL}_{\text {int }}$ for metabolism of CZX to OH-CZX in the hepatic microsomal fraction was comparable to that in controls (Figure 2, Table 1), suggesting a comparable CYP2E1 activity in HL rats. This is consistent with the unchanged expression level of hepatic CYP2E1 in HL rats (Figure 1). The free fractions of CZX in plasma are comparable between control and HL rats, based on the protein binding study. Although there has been no study of the changes in the hepatic blood flow rate in HL rats, the decreased hepatic blood flow in HL rats as a result of minimal fatty changes of the liver was suggested based on slowed $\mathrm{CL}_{\mathrm{NR}}$ of verapamil, a drug with a high hepatic extraction ratio, in $\mathrm{HL}$ rats (11). We concluded that a comparable $\mathrm{CL}_{\text {int }}$ for metabolism of CZX to OH-CZX and free fraction of CZX between control and HL rats resulted in a comparable $\mathrm{CL}_{\mathrm{NR}}$ of CZX.

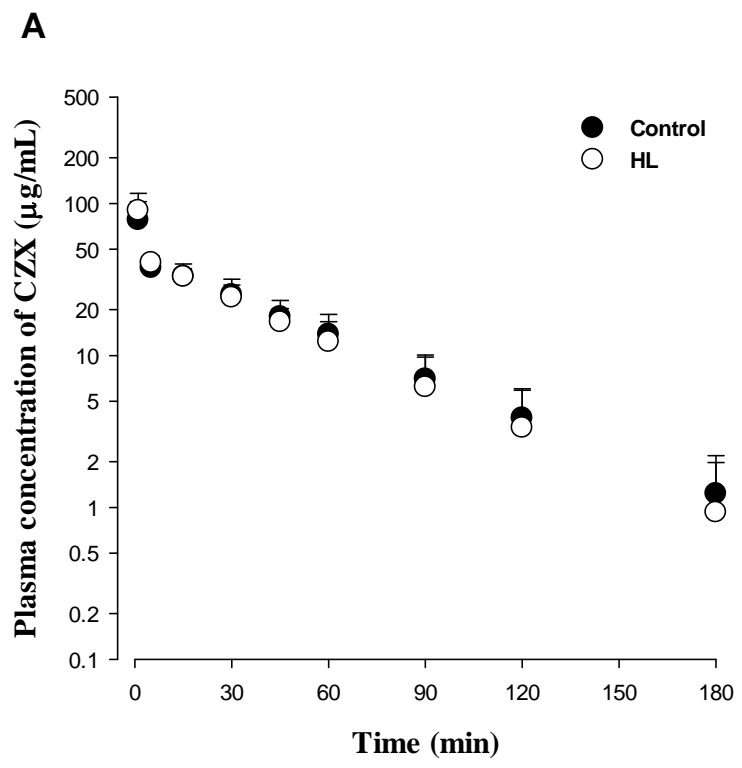

B

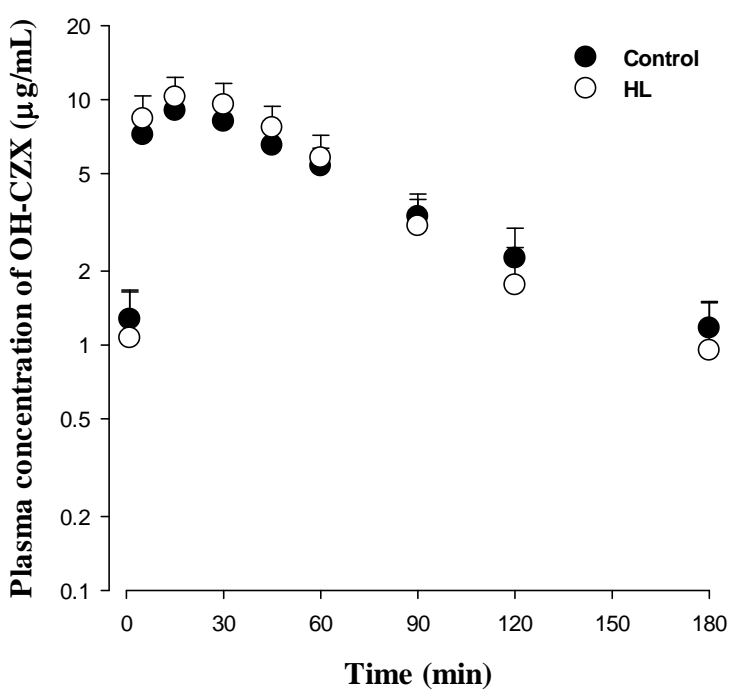

Figure 3. Mean arterial plasma concentration-time profiles (mean \pm SD) of CZX (A) and OH-CZX (B) after a single intravenous administration of $20 \mathrm{mg} / \mathrm{kg}$ CZX to control $(n=9)$ and HL $(n=10)$ rats. 
Table 2. Pharmacokinetic parameters of CZX and OH-CZX (mean \pm SD) after intravenous administration of $20 \mathrm{mg} / \mathrm{kg} \mathrm{CZX}$ to control and HL rats.

\begin{tabular}{|c|c|c|c|c|c|c|}
\hline \multirow[b]{2}{*}{ Initial body weight $(\mathrm{g})^{\mathrm{a}}$} & \multicolumn{3}{|c|}{ Control $(n=9)$} & \multicolumn{3}{|c|}{$\operatorname{HL}(n=10)$} \\
\hline & 281 & \pm & 7.41 & 285 & \pm & 13.7 \\
\hline Final body weight $(g)^{b}$ & 289 & \pm & 5.27 & 293 & \pm & 13.2 \\
\hline \multicolumn{7}{|l|}{ Plasma lipid profile } \\
\hline Total cholesterol (mg/dl) & 82.0 & \pm & 14.6 & 317 & \pm & $38.5^{* * *}$ \\
\hline Triglyceride (mg/dl) & 67.8 & \pm & 26.6 & 759 & \pm & $430^{* * *}$ \\
\hline \multicolumn{7}{|l|}{$\mathrm{CZX}$} \\
\hline $\operatorname{AUC}(\mu \mathrm{g} \cdot \min / \mathrm{ml})$ & 2270 & \pm & 652 & 2170 & \pm & 549 \\
\hline Terminal half-life (min) & 32.8 & \pm & 10.0 & 28.4 & \pm & 10.7 \\
\hline $\operatorname{MRT}(\min )$ & 47.3 & \pm & 12.4 & 41.9 & \pm & 14.5 \\
\hline $\mathrm{CL}(\mathrm{ml} / \mathrm{min} / \mathrm{kg})$ & 9.52 & \pm & 2.83 & 9.86 & \pm & 2.88 \\
\hline $\mathrm{CL}_{\mathrm{R}}(\mathrm{ml} / \mathrm{min} / \mathrm{kg})$ & 0.0806 & \pm & 0.0910 & 0.153 & \pm & 0.139 \\
\hline $\mathrm{CL}_{\mathrm{NR}}(\mathrm{ml} / \mathrm{min} / \mathrm{kg})$ & 9.44 & \pm & 2.79 & 9.71 & \pm & 2.81 \\
\hline$V_{\mathrm{ss}}(\mathrm{ml} / \mathrm{kg})$ & 429 & \pm & 97.3 & 382 & \pm & 53.5 \\
\hline $\mathrm{Ae}_{0-24 \mathrm{~h}}(\%$ of CZX dose $)$ & 0.848 & \pm & 0.774 & 1.49 & \pm & 1.25 \\
\hline \multicolumn{7}{|l|}{$\mathrm{OH}-\mathrm{CZX}$} \\
\hline $\operatorname{AUC}(\mu \mathrm{g} \cdot \min / \mathrm{ml})$ & 829 & \pm & 121 & 836 & \pm & 185 \\
\hline Terminal half-life (min) & 55.1 & \pm & 8.67 & 46.0 & \pm & 12.4 \\
\hline$C_{\max }(\mu \mathrm{g} / \mathrm{ml})$ & 9.10 & \pm & 1.63 & 10.5 & \pm & 2.19 \\
\hline$T_{\max }(\min )^{\mathrm{c}}$ & \multicolumn{3}{|c|}{$15(15-30)$} & \multicolumn{3}{|c|}{$15(5-30)$} \\
\hline $\mathrm{Ae}_{0-24 \mathrm{~h}, \text { total OH-CZX }}(\%$ of CZX dose $)$ & 86.6 & \pm & 26.2 & 102 & \pm & 22.6 \\
\hline $\mathrm{Ae}_{0-24}$ h, free OH-CZX $(\%$ of CZX dose $)$ & 37.7 & \pm & 13.7 & 40.4 & \pm & 15.4 \\
\hline $\mathrm{AUC}_{\mathrm{OH}-\mathrm{CZX}} / \mathrm{AUC}_{\mathrm{CZX}}$ ratio & 0.387 & \pm & 0.102 & 0.410 & \pm & 0.123 \\
\hline $\begin{array}{l}{ }^{\mathrm{a}} \text { Measured just before treatment. } \\
{ }^{\mathrm{b}} \text { Measured just before experiment. } \\
{ }^{\mathrm{c}} \text { Median (range) }\end{array}$ & 0.001 , & & & & & \\
\hline
\end{tabular}

The pharmacokinetic parameters of $\mathrm{OH}-\mathrm{CZX}$, including its formation ratio $\left(\mathrm{AUC} \mathrm{CH}_{\mathrm{OH}}\right.$ ${ }_{\mathrm{CZX}} / \mathrm{AUC}_{\mathrm{CZX}}$ ratio), were also comparable between control and $\mathrm{HL}$ rats. This is again due to the similar $\mathrm{CL}_{\text {int }}$ for metabolism of CZX to OH-CZX in the hepatic microsomal fraction from control and $\mathrm{HL}$ rats as a result of the comparable CYP2E1 expression and activity between the two groups. Based on the similar urinary recovery of both free and total $\mathrm{OH}-\mathrm{CZX}$ in control and $\mathrm{HL}$ rats, urinary excretion of conjugated $\mathrm{OH}-\mathrm{CZX}$ was also unchanged in HL rats. This result suggests that the conjugation reaction of $\mathrm{OH}-$ CZX, such as its glucuronidation, was also comparable in control and HL rats.

In summary, hepatic metabolism of CZX to $\mathrm{OH}-\mathrm{CZX}$ was unchanged in HL rats, itself a result of unchanged CYP2E1 expression and activity. As a result, HL rats showed comparable pharmacokinetics of CZX and OH-CZX following intravenous CZX administration. Although possible induction of CYP2E1 in HL rats had been hypothesized based on the fact that fatty acids are substrates and inducers of CYP2E1, our results suggested that HL states did not affect the expression and activity of CYP2E1. This is the first study to evaluate CYP2E1 expression and activity in HL rats and their effects on the pharmacokinetics of a CYP2E1 probe drug, CZX. As is the case for any animal model, caution is necessary in extrapolating these findings to humans. Nevertheless, these findings have potential therapeutic implications assuming that this model qualitatively reflects similar changes in patients with HL.

\section{ACKNOWLEDGEMENTS}

This research was supported by Basic Science Research Program through the National Research 
Foundation of Korea (NRF) funded by the Ministry of Science, ICT \& Future Planning (Grant No.: 2012R1A1A1005896) and by the Research Fund, 2012 of The Catholic University of Korea (M-2012-B0002-00031).

\section{REFERENCES}

1. Raasch, R.H., Hyperlipidemias, in Young LY: Koda-Kimble MA (eds), Applied Therapeutics. The Clinical Use of Drugs, Edwards Brothers, Ann Arbor, MI, pp 1743-1760, 1988.

2. Eliot LA, Jamali F. Pharmacokinetics and pharmacodynamics of nifedipine in untreated and atorvastatin-treated hyperlipidemic rats. J Pharmacol Exp Ther, 1999; 291:188-193.

3. Eliot LA, Foster RT, Jamali F. Effects of hyperlipidemia on the pharmacokinetics of nifedipine in the rat. Pharm Res, 1999; 16:309313.

4. Shayeganpour A, Korashy H, Patel JP, El-Kadi AO, Brocks DR. The impact of experimental hyperlipidemia on the distribution and metabolism of amiodarone in rat. Int J Pharm, 2008; 361:7886.

5. Shayeganpour A, Jun AS, Brocks DR. Pharmacokinetics of amiodarone in hyperlipidemic and simulated high fat-meal rat models. Biopharm Drug Dispos, 2005; 26:249257.

6. Sugioka N, Haraya K, Maeda Y, Fukushima K, Takada K. Pharmacokinetics of human immunodeficiency virus protease inhibitor, nelfinavir, in poloxamer 407-induced hyperlipidemic model rats. Biol Pharm Bull, 2009; 32:269-275.

7. Kobuchi S, Fukushima K, Shibata M, Ito Y, Sugioka N, Takada K. Pharmacokinetics of clomipramine, an antidepressant, in poloxamer 407-induced hyperlipidaemic model rats. J Pharm Pharmacol, 2011; 63:515-523.

8. Lee JH, Oh JH, Lee YJ. Effects of experimental hyperlipidaemia on the pharmacokinetics of docetaxel in rats. Xenobiotica, 2011; 41:797-804.

9. Brocks DR, Hamdy DA, Ben-Eltriki M, Patel JP, El-Kadi AO. Effect of rat serum lipoproteins on mRNA levels and amiodarone metabolism by cultured primary rat hepatocytes. J Pharm Sci, 2013; 102:262-270.

10. Lee YS, Kim YW, Kim SG, Lee I, Lee MG, Kang HE. Effects of poloxamer 407-induced hyperlipidemia on the pharmacokinetics of carbamazepine and its 10,11-epoxide metabolite in rats: Impact of decreased expression of both CYP3A1/2 and microsomal epoxide hydrolase. Eur Neuropsychopharmacol, 2012; 22:431-440.

11. Lee YS, Yoon JN, Yoon IS, Lee MG, Kang HE. Pharmacokinetics of verapamil and its metabolite norverapamil in rats with hyperlipidaemia induced by poloxamer 407 . Xenobiotica, 2012; 42:766774.
12. Chtioui H, Semela D, Ledermann M, Zimmermann A, Dufour JF. Expression and activity of the cytochrome P450 2E1 in patients with nonalcoholic steatosis and steatohepatitis. Liver Int, 2007; 27:764-771.

13. Mehvar R, Vuppugalla R. Hepatic disposition of the cytochrome P450 2E1 marker chlorzoxazone and its hydroxylated metabolite in isolated perfused rat livers. J Pharm Sci, 2006; 95:1414 1424.

14. Jung HY, Kang HE, Choi YH, Kim SH, Lee MG. Time-dependent effects of Klebsiella pneumoniae endotoxin on the pharmacokinetics of chlorzoxazone and its main metabolite, 6hydroxychlorzoxazone, in rats: restoration of the parameters in 96 hour in KPLPS rats to control levels. Biopharm Drug Dispos, 2009; 30:485-493.

15. Lee JH, Lee MG. Telithromycin pharmacokinetics in rat model of diabetes mellitus induced by alloxan or streptozotocin. Pharm Res, 2008; 25:1915-1924.

16. Bradford MM. A rapid and sensitive method for the quantitation of microgram quantities of protein utilizing the principle of protein-dye binding. Anal Biochem, 1976; 72:248-254.

17. Duggleby RG. Analysis of enzyme progress curves by nonlinear regression. Methods Enzymol, 1995; 249:61-90.

18. Boudinot FD, Jusko WJ. Fluid shifts and other factors affecting plasma protein binding of prednisolone by equilibrium dialysis. J Pharm Sci, 1984; 73:774-780.

19. Øie S, Guentert TW. Comparison of equilibrium time in dialysis experiments using spiked plasma or spiked buffer. J Pharm Sci, 1982; 71:127-128.

20. Ahn CY, Bae SK, Jung YS, Lee I, Kim YC, Lee MG, Shin WG. Pharmacokinetic parameters of chlorzoxazone and its main metabolite, 6hydroxychlorzoxazone, after intravenous and oral administration of chlorzoxazone to liver cirrhotic rats with diabetes mellitus. Drug Metab Dispos, 2008; 36:1233-1241.

21. Wong A, Bandiera SM. Induction of hepatic cytochrome $\mathrm{P} 450$ 2B and $\mathrm{P} 450$ 3A isozymes in rats by zolazepam, a constituent of Telazol. Biochem Pharmacol, 1998; 55:201-207.

22. Plate AY, Crankshaw DL, Gallaher DD. The effect of anesthesia by diethyl ether or isoflurane on activity of cytochrome P450 2E1 and P450 reductases in rat liver. Anesth Analg, 2005; 101:1063-1064.

23. Moon YJ, Lee AK, Chung HC, Kim EJ, Kim SH, Lee DC, Lee I, Kim SG, Lee MG. Effects of acute renal failure on the pharmacokinetics of chlorzoxazone in rats. Drug Metab Dispos, 2003; 31:776-784.

24. Chiou WL. Critical evaluation of the potential error in pharmacokinetic studies using the linear trapezoidal rule method for the calculation of the area under the plasma level-time curve. J Pharmacokinet Biopharm, 1978; 6:539-546. 
25. Gibaldi, M., Perrier, D., Pharmacokinetics, 2nd ed. Marcel-Dekker, New York, NY, 1982.

26. Johnston TP, Palmer WK. Mechanism of poloxamer 407-induced hypertriglyceridemia in the rat. Biochem Pharmacol, 1993; 46:1037-1042.

27. Leon C, Wasan KM, Sachs-Barrable K, Johnston TP. Acute P-407 administration to mice causes hypercholesterolemia by inducing cholesterolgenesis and down-regulating lowdensity lipoprotein receptor expression. Pharm Res, 2006; 23:1597-1607.

28. Palmer WK, Emeson EE, Johnston TP. The poloxamer 407-induced hyperlipidemic atherogenic animal model. Med Sci Sports Exerc, 1997; 29:1416-1421.
29. Kaneko I, Fukumori Y, Fukuda T, Takeuchi Y. Disposition of chlorzoxazone dissolved in polyethylene glycol in rats. Yakuzaigaku, 1990; 50: $166-171$.

30. Gao N, Zou D, Qiao HL, Concentration-dependent inhibitory effect of Baicalin on the plasma protein binding and metabolism of chlorzoxazone, a CYP2E1 probe substrate, in rats in vitro and in vivo. PLoS One, 2013; 8:e53038.

31. Davies B, Morris T. Physiological parameters in laboratory animals and humans. Pharm Res, 1993; 10:1093-1095.

32. Wilkinson GR, Shand DG. A physiological approach to hepatic drug clearance. Clin Pharmacol Ther, 1975; 18:377-390. 